\title{
Non-Convulsive Status Epilepticus in Hepatic Encephalopathy: A Case Series and Review of the Literature
}

\author{
Anthony Nguyen ${ }^{1}$,Mohammad Ali Butt ${ }^{2}$, Shubhra Upadhyay ${ }^{1}$, Abu Baker Sheikh ${ }^{1}$, Rahul Shekhar ${ }^{3}$ \\ ${ }^{1}$ University of New Mexico Health Sciences Center, Department of Internal Medicine, Albuquerque, NM, USA \\ ${ }^{2}$ Allegheny General Hospital, Department of Internal Medicine, Pittsburgh, PA, USA
}

${ }^{3}$ Division of Hospital Medicine, University of New Mexico Health Sciences Center, Department of Internal Medicine, Albuquerque, NM, USA

Received: 10/01/2022

Accepted: $27 / 01 / 2022$

Published: $22 / 02 / 2022$

\begin{abstract}
How to cite this article: Nguyen A, Butt MA, Upadhyay S, Sheikh BA, Shekhar R. Non-convulsive status epilpeticus in hepatic encephalopathy: a case series and review of the literature. EJCRIM 2022;9: doi:10.12890/2022_003179.
\end{abstract}

Conflicts of Interests: The authors declare there are no competing interests.

This article is licensed under a Commons Attribution Non-Commercial 4.0 License

\section{ABSTRACT}

Hepatic encephalopathy is a common complication in chronic liver disease and cirrhosis. Here we describe two patients with hepatic encephalopathy who did not respond to standard empiric treatment and were found to have non-convulsive status epilepticus. Both patients improved with antiepileptic therapy. Non-convulsive status epilepticus should be considered in the differential diagnosis of patients with suspected hepatic encephalopathy who do not respond to empiric treatment.

\section{LEARNING POINTS}

- Non-convulsive status epilepticus (NCSE) is a rare complication of hepatic encephalopathy (HE).

- Clinical evaluation should be used to rule out different causes of altered mental status in patients with chronic liver disease.

- Consider EEG to diagnose NCSE in patients with suspected HE not responding to empiric treatment.

\section{KEYWORDS}

Hepatic encephalopathy, non-convulsive status epilepticus, electroencephalogram

\section{INTRODUCTION}

In the USA, more than 4.5 million people have chronic liver disease ${ }^{[1]}$. Some $30-45 \%$ of patients with cirrhosis can develop hepatic encephalopathy (HE) leading to significant morbidity and mortality ${ }^{[2,3]}$. The clinical spectrum of HE extends from mild cognitive impairment to coma ${ }^{[4]}$. Non-convulsive status epilepticus (NCSE) is a state of ongoing seizure activity for at least 30 min without convulsive clinical manifestations. It requires an electroencephalogram (EEG) for confirmation. Due to similarities in the clinical spectrum of HE and NCSE, the latter, more morbid and uncommon diagnosis can be missed ${ }^{[5,6]}$. Here we present two patients with liver cirrhosis without a previous history of seizures, who presented with HE and were diagnosed with NCSE.

\section{CASE DESCRIPTIONS}

\section{Case 1}

A 47-year-old woman with a medical history of class III obesity, alcohol use disorder with dependence, and upper gastrointestinal bleed presented with a 4-day history of confusion, falls and jaundice. She was never formally diagnosed with cirrhosis. Somnolence, dilated pupils, scleral icterus, distended abdomen, +2 pitting oedema in the legs, and asterixis were present on examination. Leucocytosis, anaemia, hyponatremia and deranged liver function tests were present on initial evaluation. Liver ultrasound showed hepatomegaly with mild ascites. 
The patient was diagnosed with $\mathrm{HE}$ and alcoholic hepatitis. On admission, she had an acute kidney injury. Lactulose was commenced. Due to lack of symptomatic improvement, rifaximin was added. Her last alcoholic drink was about 3 weeks before presentation, ruling out alcohol withdrawal. On the 6th hospital day, her mental status improved and was normal for 3 days before deteriorating on the 9th day. She had an adequate response to lactulose and rifaximin with three to five bowel movements daily. Her kidney injury further worsened and she was diagnosed with hepatorenal syndrome with an albumin challenge test. Due to lack of response, EEG was ordered. She was found to be in NCSE (Fig. 1). She was given stat intravenous lorazepam, levetiracetam, and transferred to the intensive care unit, resolving her NCSE. Lactulose, rifaximin and tube feeds via a nasogastric tube were continued. Her course was complicated with aspiration pneumonia. Multiple repeat EEG were negative for seizure activity and she was maintained on levetiracetam. Haemodialysis was also started due to persistent oliguria before subsequent discharge to a skilled nursing facility.

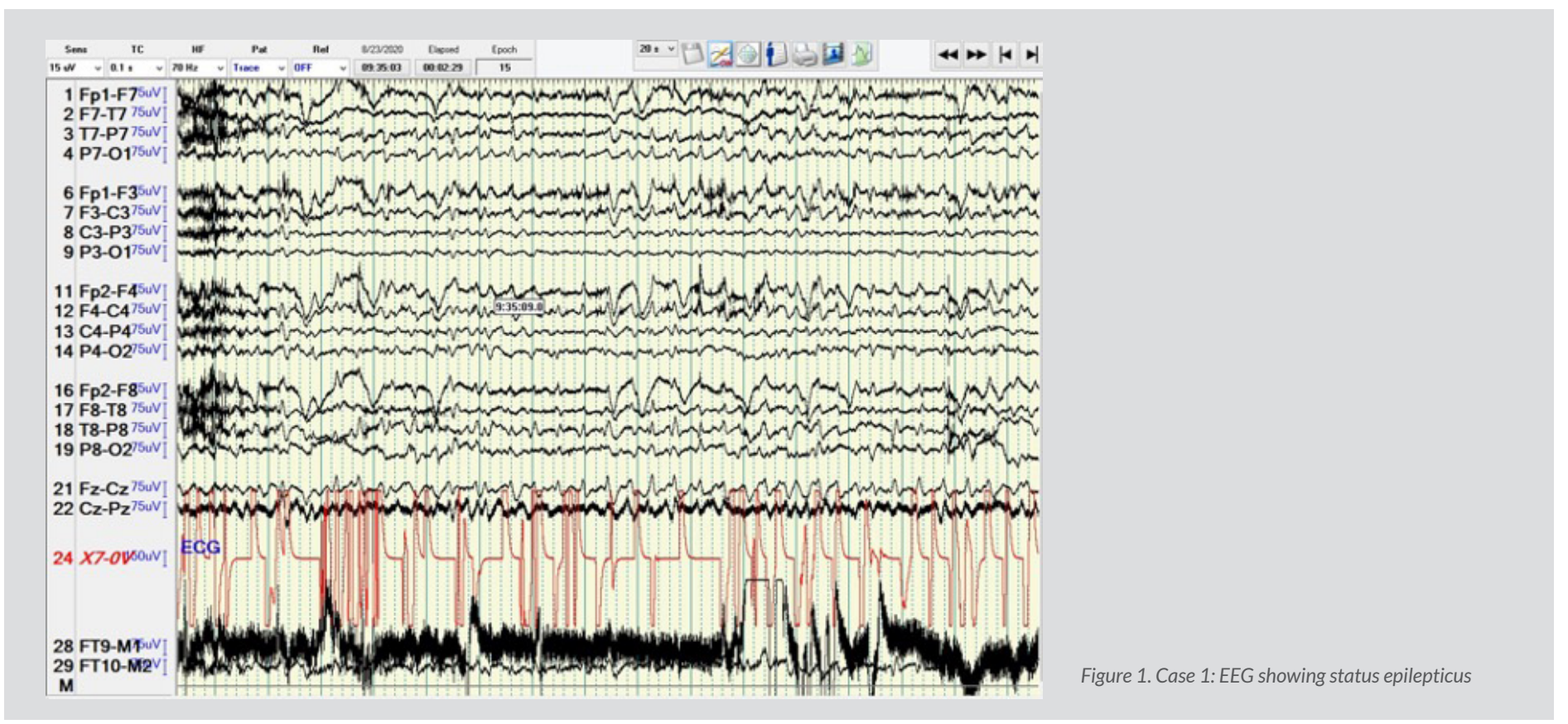

Case 2

A 53-year-old man with a history of hepatitis C, hepatitis B, liver cirrhosis, upper gastrointestinal bleed, and intravenous drug use, presented with one episode of haematemesis and altered sensorium. He was not actively drinking and was compliant with his lactulose. His ammonia level was 323 and he was started on rectal enema. AST, ALP and INR levels were elevated. Albumin levels were low. Somnolence, abdominal distension and asterixis were noted. He was intubated for airway protection. During endoscopy, large, active varices found in the lower third of the oesophagus, were banded. Afterwards, his electrocardiogram showed ST-segment elevations. Cardiac catheterization revealed nonobstructive coronary artery disease. He continued to be obtunded on the 2nd hospital day so an EEG was ordered that showed NCSE (Fig. 2). He was successfully treated with intravenous midazolam bolus, levetiracetam load and propofol (Fig. 3). Magnetic resonance imaging of the brain revealed hyperintense signals in the bilateral medial thalami and putamen (Fig. 4). On the 5th hospital day, he had transient leftsided facial droop and left-sided weakness. Repeat imaging studies were unremarkable. He was discharged to a skilled nursing facility and levetiracetam was discontinued.

\section{DISCUSSION}

$\mathrm{HE}$, characterized by altered mental status, occurs in chronic liver disease. The multifactorial pathophysiology has many culprit agents including cytokines, cerebral oedema, and intracranial hypertension ${ }^{[7,8]}$. Ammonia, a major culprit, cannot be metabolized in patients with chronic liver disease and is, therefore, shunted to the systemic circulation without detoxification ${ }^{[9]}$. The management of HE involvesreduction of either ammonia production and absorption ${ }^{[10]}$.

The pathophysiology of seizures in HE remains unknown. Elevated ammonia results in increased glutamine production that promotes generalized swelling leading to neuronal dysfunction [11, 12]. The permeability of the blood-brain barrier for ammonia increases during inflammation, enhancing toxicity ${ }^{[12]}$. The epileptiform activity in EEG, seizures or status epilepticus (SE), generally imply a poor prognosis because they develop in end-stage liver disease ${ }^{[6,13]}$. 
Figure 2. Case 2: EEG showing status epilepticus
Figure 3. Case 2: EEG showing status epilepticus after burst suppression

In our study, neither patient responded to ammonia-reducing treatment and both were diagnosed with NCSE on EEG. With proper treatment, their mentation improved and they were discharged. A high level of clinical suspicion is required to identify NCSE that is associated with elevated mortality ${ }^{[5]}$. Gursky et al. showed that HE events were associated with subsequent admissions for epilepsy or SE ${ }^{[14]}$. This effect was even higher for admission with SE, with a three- to fivefold likelihood of admission with SE in the next 6 months ${ }^{[14]}$. Table 1 summarizes the four case reports found in PubMed, CINAHL and Web of Science ${ }^{[15-18]}$.

\section{CONCLUSION}

NCSE should be considered in the differential diagnosis of patients with HE who do not respond to the usual treatment. Further studies are needed to investigate NCSE. 


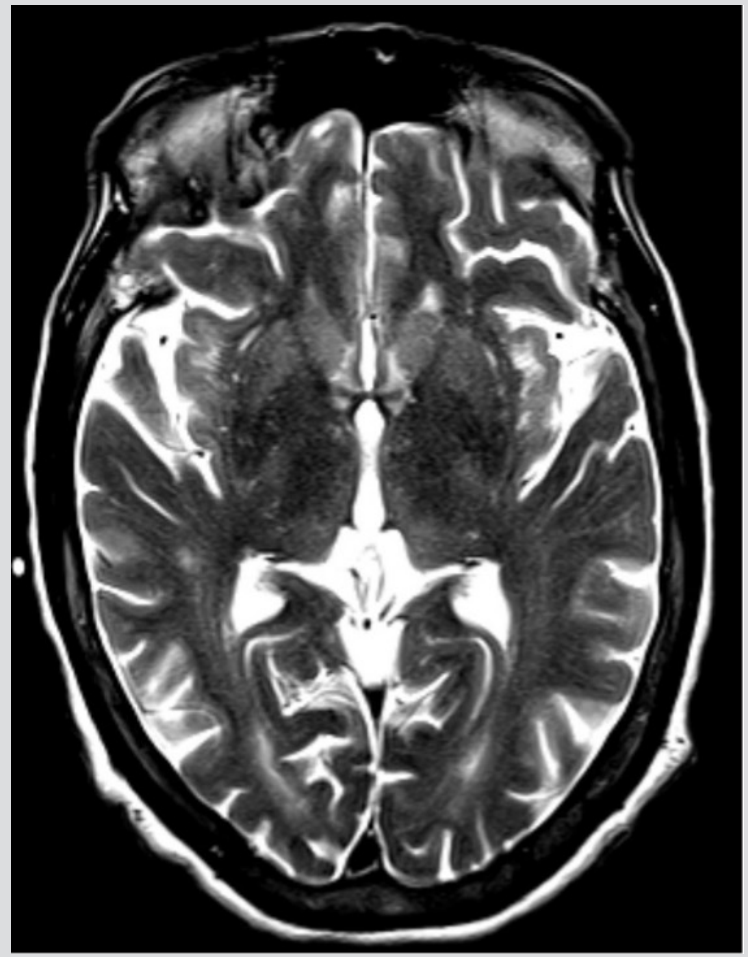

Figure 4. Case 2: MRI of the brain without contrast. Axial section of T2 series showing hyper-intense signa in the bilateral medial thalami and putamen

\begin{tabular}{|c|c|c|c|c|c|c|}
\hline Author & Age/sex & Liver disease & Ammonia level & EEG findings & Treatment & Outcome \\
\hline Hor et al. [15] & 38 , male & $\begin{array}{l}\text { Alcoholic liver } \\
\text { disease }\end{array}$ & $\begin{array}{l}227(6-47 \\
\mu \mathrm{mol} / \mathrm{l})\end{array}$ & $\begin{array}{l}\text { Intermittent spike-and-wave pat- } \\
\text { terns, predominantly in the right } \\
\text { hemisphere-NCSE }\end{array}$ & $\begin{array}{l}\text { Levetirace- } \\
\text { tam, propofol }\end{array}$ & Discharged \\
\hline Jhun et al. [16] & 64 , male & $\begin{array}{l}\text { Hepatitis C } \\
\text { status post liver } \\
\text { transplant }\end{array}$ & $\begin{array}{l}501(15-55 \\
\mu \mathrm{mol} / \mathrm{l})\end{array}$ & NCSE & $\begin{array}{l}\text { Midazolam, } \\
\text { phenytoin }\end{array}$ & $\begin{array}{l}\text { Transferred to } \\
\text { other institution }\end{array}$ \\
\hline Jo et al. [17] & 52 , male & $\begin{array}{l}\text { Hepatitis B and } \\
\text { HCC }\end{array}$ & $\begin{array}{l}88(10-47 \\
\mu \mathrm{mol} / \mathrm{l})\end{array}$ & $\begin{array}{l}\text { Generalized sequential rhythmic } \\
\text { delta to theta activity, with decre- } \\
\text { asing termination and increasing } \\
\text { onset - NCSE }\end{array}$ & Levetiracetam & Died \\
\hline Badshah et al. [18] & 45 , male & Hepatitis C & 50 (not given) & $\begin{array}{l}\text { Ongoing seizure activity from the } \\
\text { right parietal lobe - NCSE }\end{array}$ & Levetiracetam & Discharged \\
\hline
\end{tabular}

Table 1. Summary of articles found in databases

EEG, electroencephalogram; HCC, hepatocellular carcinoma; NCSE, non-convulsive status epilepticus. 


\section{REFERENCES}

1. Centers for Disease Control and Prevention. FastStats - Chronic Liver Disease or Cirrhosis. Available from: https://www.cdc.gov/nchs/fastats/liver-disease.htm (accessed 14 August 2021).

2. Poordad FF. Review article: the burden of hepatic encephalopathy. Aliment Pharmacol Ther 2007;25(Suppl. 1):3-9. doi: 10.1111/j.1746-6342.2006.03215.x.

3. Bajaj JS, O'Leary JG, Tandon P, Wong F, Garcia-Tsao G, Kamath PS, et al. Hepatic encephalopathy is associated with mortality in patients with cirrhosis independent of other extrahepatic organ failures. Clin Gastroenterol Hepatol 2017;15(4):565-574.e4. doi: 10.1016/j.cgh.2016.09.157.

4. Ferenci P. Hepatic encephalopathy in adults: clinical manifestations and diagnosis. UpToDate. Available from: https://www.uptodate.com/contents/hepatic-encephalopathyin-adults-clinical-manifestations-and-diagnosis (accessed 14 August 2021).

5. Kaplan PW. The clinical features, diagnosis, and prognosis of nonconvulsive status epilepticus. Neurologist 2005;11(6):348-361. doi: 10.1097/01.nrl.0000162954.76053.d2

6. Rudler M, Marois C, Weiss N, Thabut D, Navarro V, Brain-Liver Pitié-Salpêtrière Study Group (BLIPS). Status epilepticus in patients with cirrhosis: how to avoid misdiagnosis in patients with hepatic encephalopathy. Seizure 2017:45:192-197. doi: 10.1016/j.seizure.2016.12.011.

7. Donovan JP, Schafer DF, Shaw BW, Sorrell MF. Cerebral oedema and increased intracranial pressure in chronic liver disease. Lancet 1998;351(9104):719-721. doi: 10.1016/ S0140-6736(97)07373-X.

8. Elwir S, Rahimi RS. Hepatic encephalopathy: an update on the pathophysiology and therapeutic options. J Clin Transl Hepatol 2017;5(2):142-151. doi: 10.14218/ JCTH.2016.00069.

9. Richardson AJ, McKain N, Wallace RJ. Ammonia production by human faecal bacteria, and the enumeration, isolation and characterization of bacteria capable of growth on peptides and amino acids. BMC Microbiol 2013;13(1):6. doi: 10.1186/1471-2180-13-6.

10. Wijdicks EFM. Hepatic encephalopathy. N Engl J Med 2016;375(17):1660-1670. doi: 10.1056/NEJMra1600561.

11. Gerber T, Schomerus H. Hepatic encephalopathy in liver cirrhosis: pathogenesis, diagnosis and management. Drugs 2000;60(6):1353-1370. doi: 10.2165/00003495200060060-00008.

12. Tapper EB, Jiang ZG, Patwardhan VR. Refining the ammonia hypothesis: a physiology-driven approach to the treatment of hepatic encephalopathy. Mayo Clin Proc 2015;90(5):646-658. doi: 10.1016/j.mayocp.2015.03.003.

13. Ficker DM, Westmoreland BF, Sharbrough FW. Epileptiform abnormalities in hepatic encephalopathy. J Clin Neurophysiol 1997;14(3):230-234. doi: 10.1097/00004691$199705000-00008$

14. Gursky JM, Rossi KC, Jetté N, Dhamoon MS. Exacerbation of hepatic cirrhosis may trigger admission for epilepsy and status epilepticus. Epilepsia 2020;61(3):400-407. doi: 10.1111/epi.16437.

15. Hor S, Chen CY, Tsai ST. Propofol pump controls nonconvulsive status epilepticus in a hepatic encephalopathy patient: a case report. World J Clin Cases 2019;7(18):2831-2837. doi: 10.12998/wjcc.v7.i18.2831.

16. Jhun P, Kim H. Nonconvulsive status epilepticus in hepatic encephalopathy. West J Emerg Med 2011;12(4):372-374. doi: 10.5811/westjem.2011.1.2125.

17. Jo YM, Lee SW, Han SY, Baek YH, Ahn JH, Choi WJ, et al. Nonconvulsive status epilepticus disguising as hepatic encephalopathy. World J Gastroenterol 2015;21(16):51055109. doi: 10.3748/wjg.v21.i16.5105.

18. Badshah MB, Riaz H, Aslam S, Badshah MB, Korsten MA, Munir MB. Complex partial non-convulsive status epilepticus masquerading as hepatic encephalopathy: a case report. J Med Case Rep 2012;6(1):2-4. doi: 10.1186/1752-1947-6-422. 